\title{
Produção dos clones de cará Liso e Caramujo conduzidos em forma rasteira e tutorada.
}

\author{
Néstor A. Heredia Z. ${ }^{1}$; Maria do Carmo Vieira; Raquel Griep ${ }^{2}$ \\ UFMS - DCA, C. Postal 533, 79804-970 Dourados - MS.
}

\begin{abstract}
RESUMO
Foram estudados dois clones de cará (Liso e Caramujo), sob duas formas de condução das plantas (rasteiro e tutorado) em dez épocas de colheita (dos 60 aos 330 dias após o plantio, em intervalos mensais), plantados em Latossolo Roxo distrófico, textura argilosa pesada. Os tratamentos foram arranjados no fatorial $2 \times 2$, no delineamento experimental de blocos casualizados, com três repetições, em cada época de colheita, totalizando 120 parcelas. As parcelas de $15 \mathrm{~m}^{2}$ foram compostas de dez e de cinco plantas, com espaçamento de $1,5 \mathrm{~m} \times 1,0 \mathrm{~m} \mathrm{e} 3,0 \mathrm{~m} \times 1,0 \mathrm{~m}$ para a cultura tutorada e para a rasteira, respectivamente. A propagação do cará foi feita com pedaços de rizomas de $\pm 150 \mathrm{~g}$, em covas. A irrigação se fez por sulcos. O tutoramento foi realizado seguindo o sistema de haste cruzada. Para conhecer as características produtivas dos clones, nas duas formas de condução, em cada colheita foram avaliadas as produções de matérias frescas de ramos + folhas, de rizomas e de tubérculos e a composição nutritiva desses. A produção de matéria fresca de ramos + folhas foi dependente do clone e da forma de condução da cultura, sem ter associação entre os dois fatores. Quando relacionadas as produções de matérias frescas de tubérculos e de rizomas foi observado que o 'Liso' produziu somente rizomas, com máxima produção aos 285 dias, independente da forma de condução da cultura. A forma de produção do clone Caramujo mostrou dependência da forma de condução $(92,06 \%$ de rizomas e $7,94 \%$ de tubérculos, quando tutorada e $46,12 \%$ de rizomas e $53,88 \%$ de tubérculos, quando rasteira). As análises sobre valor nutritivo dos rizomas e tubérculos mostraram que os rizomas do clone Liso foram os melhores. As produções totais dos clones de cará (tubérculos + rizomas) mostraram que o Caramujo $(50,266 \mathrm{t} / \mathrm{ha})$ produziu $181,58 \%$ a mais que o Liso. As plantas rasteiras dos dois clones de cará produziram mais que as tutoradas e por isso, recomenda-se a condução rasteira para os dois clones.
\end{abstract}

Palavras-chave: Dioscorea alata, Dioscorea cayennensis, forma de condução, produtividade, rizomas, tubérculos.

\begin{abstract}
Production of Liso and Caramujo yam clones carried out in creeping and stakeing plants.

Two yam clones (Liso and Caramujo) were studied under two conduction methods (creeping and stakeing) at ten harvesting dates (from the $60^{\text {th }}$ to $330^{\text {th }}$ day after transplanting, with 30 day intervals), on a dark clay texture distrophic Eutrustox soil. Treatments were arranged in a $2 \times 2$ factorial scheme in a complete randomized block design with three replications at each harvest date, totalling 120 plots. $15 \mathrm{~m}^{2}$ plots were composed of ten and five plants, spaced $1.5 \times 1.0$ $\mathrm{m}$ and $3.0 \times 1.0 \mathrm{~m}$ for stakeing and creeping culture respectively. Yam propagation was carried out using rhizome pieces $( \pm 150 \mathrm{~g})$ in pits, and with irrigation by furrow infiltration, and the crossed stem system for stakeing. For the two clones, under the two conduction types, fresh matter production from branches + leaves, rhizomes and tubers and nutritive composition of rhizomes and tubers were obtained at each monthly harvest. Fresh matter production was influenced by clones and by plant conduction, with no interaction between the two factors. When rhizome and tuber material were related, it was observed that the clone Liso produced only rhizomes, with a maximum fresh matter production reached 285 days after planting, independent of plant conduction form. For the clone Caramujo, clone production was influenced by plant conduction method $(92.06 \%$ rhizome and $7.94 \%$ tuber by plant stakeing, and $46.12 \%$ rhizome and $53.88 \%$ tuber by plant creeping). The clone Liso produced rhizomes and tubers with the best nutritive values. In terms of total production of rhizomes and tubers, the clone Caramujo (50.266 ton/ha) produced $181.58 \%$ more than clone Liso. The creeping method of plant conduction of both Liso and Caramujo yam clones is recommended as it resulted in a greater total production than the staking conduction method for plant cultivation.
\end{abstract}

Keywords: Dioscorea alata, Dioscorea cayennensis, plant conduction form, productivity, rhizomes, tubers.

\section{(Aceito para publicação em 30 de outubro de 1998)}

$\mathrm{O}$ cará (Dioscorea sp) é uma hortaliça com expressivo consumo mundial, em torno de 30 bilhões de toneladas por ano, sendo uma cultura em expansão, pois deixou para trás a batata-doce (Ipomoea batatas), a mandioca (Manihot esculenta) e a batatinha (Solanum tuberosum) (A Granja do Ano, 1994). É rico em proteínas, fósforo, cálcio, ferro, vitaminas $\mathrm{B}_{1}, \mathrm{~B}_{2} \mathrm{e}$ carboidratos (Abramo, 1990; A Granja

do Ano, 1994). A farinha do cará pode substituir a da mandioca e seu amido tem as mesmas características do amido do milho, tanto em sabor como em textura e cor, podendo ser empregado por indústrias alimentícias com a mesma finalidade que o amido do milho (Abramo, 1990).

Os clones de cará mais conhecidos para o cultivo são o Cará-Mimoso $(D$. alata) que produz tubérculos com boa aparência, uniformes, casca lisa, polpa amarelada e ótima qualidade culinária. O Cará-Flórida (D. alata) produz tubérculos alongados ou cilíndricos, casca marrom-clara e polpa granulosa. $\mathrm{O}$ Cará-da-Costa (D. cayennensis) é cultivado no litoral nordestino e as plantas produzem poucos tubérculos de tamanho grande (A Granja do Ano, 1994).

A propagação do cará é feita utilizando tubérculos cortados em frações

${ }^{1}$ Bolsista de produtividade em pesquisa do $\mathrm{CNPq}$

${ }^{2}$ Estudante de Iniciação Científica - PIBIC/CNPq/UFMS 
não superiores a 250 g (Abramo, 1990; A Granja do Ano, 1994). O espaçamento de plantio depende da forma de condução das plantas. Se forem utilizadas covas fundas ou montículos, as distâncias exigidas serão de $1,20 \mathrm{~m}$ x $0,80 \mathrm{~m}$. No plantio em terreno plano, os espaçamentos devem ser de $1,20 \mathrm{~m} \times 0,50 \mathrm{~m}$. Os espaçamentos citados implicam no uso de estaqueamento, uma vez que as plantas de cará são do tipo trepadeira (Abramo, 1990). Em trabalho realizado com cará como cultura rasteira, em Dourados - MS, foram utilizados espaçamentos de $0,96 \mathrm{~m} \times 2,45 \mathrm{~m} ; 1,20$ $\mathrm{m} \times 2,45 \mathrm{~m}$ e $1,60 \mathrm{~m} \times 2,45 \mathrm{~m}$ (Heredia \& Vieira, 1994).

A colheita do cará deve ser realizada quando os ramos ficarem secos, entre seis a doze meses após o plantio (Abramo, 1990), quando os tubérculos e/ou rizomas apresentarem-se com melhor qualidade culinária, tamanho e aspecto comercializável (A Granja do Ano, 1994; Heredia \& Vieira, 1994). A partir dessa fase, o agricultor pode aguardar entre três a quatro semanas para que a maturação se complete (A Granja do Ano, 1994). A produtividade da cultura depende da cultivar, variando de 15 a $20 \mathrm{t} / \mathrm{ha}$; em solos com boas condições de manejo, o produtor pode colher cerca de $25 \mathrm{t} / \mathrm{ha}$. (A Granja do Ano, 1994). Em trabalho experimental realizado em Dourados, entre 1993 e 1994, em Latossolo Roxo distrófico que há sete anos vem sendo corrigido e cultivado com hortaliças, a produção foi de 35,6 t/ha para $D$. cayennensis e $27,4 \mathrm{t} /$ ha para o D. alata tipo Cará-Flórida, utilizando população de 4.264 plantas/ ha (Heredia \& Vieira, 1994).

O objetivo do presente trabalho foi conhecer a resposta produtiva dos clones de cará Liso (D. alata) e Caramujo (D. cayennensis) com plantas conduzidas na forma rasteira ou tutorada.

\section{MATERIAL E MÉTODOS}

O trabalho foi desenvolvido na horta do Núcleo Experimental de Ciências Agrárias (NCA) da Universidade Federal de Mato Grosso do Sul (UFMS), em Dourados-MS, em Latossolo Roxo distrófico, textura argilosa pesada, entre 10 de outubro de 1995 e 10 de setembro de 1996.
Os fatores estudados foram clones de cará (Liso e Caramujo), formas de condução da cultura (rasteira e tutorada) e dez épocas de colheita (mensais, dos 60 aos 330 dias após o plantio) fatorial $2 \times 2$, no delineamento experimental de blocos ao acaso, com três repetições, totalizando 120 parcelas. As parcelas foram de $15 \mathrm{~m}^{2}$ (3,0 $\mathrm{m}$ de largura x 5,0 $\mathrm{m}$ de comprimento) e compostas de cinco plantas com espaçamento de $3,0 \mathrm{~m} \mathrm{x}$ $1,0 \mathrm{~m}$ para a cultura rasteira de dez plantas com espaçamento de $1,5 \mathrm{~m}$ x 1,0 m para a tutorada.

O terreno foi preparado mediante aração e gradagem. Para o plantio foram abertas covas de $0,30 \mathrm{~m}$ largura $\mathrm{x}$ $0,30 \mathrm{~m}$ comprimento $\times 0,20 \mathrm{~m}$ profundidade onde foi colocado o solo misturado com $50 \mathrm{~g}$ de calcário natural, $50 \mathrm{~g}$ de calcário dolomítico filler, $40 \mathrm{~g}$ de 4 24-8 e $1.000 \mathrm{~g}$ de cama de aviário semidecomposta. A propagação do cará foi feita com pedaços de rizomas de \pm 150 $\mathrm{g}$ que foram enterrados em cada cova à profundidade de $0,15 \mathrm{~m}$. A irrigação foi feita por sulcos e efetuada duas vezes por semana. As capinas foram executadas em forma manual com auxílio de enxada. Não foram utilizados agrotóxicos. O tutoramento do cará foi realizado seguindo o sistema de haste cruzada, utilizado normalmente para tomateiro de crescimento indeterminado, ou seja, usando bambus individuais apoiados $\mathrm{em}$ arame estendido a 1,80 $\mathrm{m}$ de altura.

Para conhecer as características produtivas dos clones, nas duas formas de condução, foram efetuadas colheitas a cada 30 dias, a partir dos 60 dias após o plantio, utilizando a planta central da parcela correspondente à época de colheita. Os caracteres determinados foram produção de matéria fresca de ramos mais folhas, de rizomas e/ou tubérculos, além da composição nutritiva desses. Às médias obtidas para matéria fresca foram ajustadas equações de regressão, tendo sido empregados polinômios ortogonais. A significância dos modelos foi testada pelo teste $\mathrm{F}$ e os coeficientes de regressão dos modelos selecionados pelos teste $\mathrm{t}$ (Gomes, 1992), até o nível de 5\%.

\section{RESULTADOS E DISCUSSÃO}

A produção de matéria fresca de ramos mais folhas, das plantas de cará foi dependente do clone e da forma de condução da cultura (Figura 1). As maiores produções corresponderam às plantas tutoradas com máximo aos 165 dias após o plantio para o clone Liso $(14,4 \mathrm{t} /$ ha) e aos 195 dias para Caramujo (15,8 t/ha) mostrando aumentos de $66,86 \%$ (Liso) e 17,56\% (Caramujo) em relação às plantas conduzidas em forma rasteira. Ao relacionar as produções com as populações utilizadas em cada sistema de condução das culturas determinouse que as plantas tutoradas (6.666 plantas/ha) produziram menos matéria fresca de ramos e folhas $(-16,60 \%$ para as do Liso e -41,19 para as do Caramujo) quando comparadas com as rasteiras (3.333 plantas/ha). Esse fato demonstra que nas plantas de cará houve respostas modificativas durante o seu período de crescimento (Larcher, 1986) que as adaptaram às condições rasteira ou tutorada.

Os decréscimos produtivos de matéria fresca de ramos mais folhas observados para os clones Liso e Caramujo, após 180 dias do plantio, indicam que as plantas alcançaram a máxima expansão foliar e iniciaram perdas das folhas mais velhas, com provável translocação de fotossintatos de reserva para a parte subterrânea, como ocorreu em inhame (Heredia, 1988) e em mandioquinha-salsa (Vieira, 1995). Devido às menores perdas de peso nos noventa dias posteriores à máxima produção (-44,24\% quando tutorado e $-43,37 \%$ quando rasteiro), o clone Caramujo pode ser classificado como de ciclo tardio ao relacioná-lo com o Liso que no mesmo período perdeu $53,47 \%$ e $56,78 \%$, nos sistemas tutorado e rasteiro, respectivamente.

Quando relacionadas as produções de rizomas (Figura 2) e de tubérculos (Figura 3) foi observado que o clone Liso produziu somente rizomas, mas o Caramujo produziu rizomas e tubérculos aéreos (Vidal \& Vidal, 1992; Apezzato-da-Glória, 1996), com produtividades dependentes da forma de condução da cultura. Esse fato confirma o exposto por Larcher (1986) de que o padrão de resposta de uma planta e seu específico potencial de adaptação são características geneticamente determinadas. Mas, contraria as citações de Abramo (1990) e da Granja do Ano 
(1994) de que as espécies D. alata e $D$. cayennensis produzem somente tubérculos. A maior produção de matéria fresca de rizomas do clone Liso foi alcançada aos 285 dias, tanto no tutorado $(31,139 \mathrm{t} / \mathrm{ha})$, como no rasteiro $(30,393$ t/ha), mostrando relação direta entre a senescência dos componentes aéreos (Figura 1) e o aumento de matéria fresca dos rizomas (Figura 2). Isso indica os componentes aéreos como locais temporários de reserva de água e de fotossintatos a serem translocados para o crescimento dos rizomas quando do início da senescência (Heredia, 1988). Isso seria confirmado pelas perdas de peso dos rizomas das plantas tutoradas $(25,68 \%)$ e das rasteiras $(26,78 \%)$, do cará Liso, nos 45 dias posteriores à máxima produção de matéria fresca dos rizomas, respectivamente, que coincidiu com as mais baixas quantidades de matéria fresca de ramos + folhas (Figura 1) e que corresponderia à época de amadurecimento dos rizomas, quando haveria maior perda de água dos tecidos sem ter uma fonte de recuperação.

Em relação à produção total dos clones (rizomas + tubérculos), aos 330 dias após o plantio, foi observado que não tiveram interferência significativa dos tratamentos mas a forma de produção do Caramujo dependeu deles. Assim, quando as plantas do clone Caramujo foram tutoradas, a produção maior foi de rizomas $(92,06 \%)$, mas quando rasteiras a produção foi de $46,12 \%$ de rizomas e $53,88 \%$ de tubérculos. Esse fato mostra que, embora a planta inteira seja autotrófica, seus órgãos individuais são heterotróficos, dependendo uns dos outros para obter nutrientes e fotossintatos (Strauss, 1983). Além disso, confirma a hipótese de que os ramos e folhas são locais de armazenamento temporário de fotossintatos (Hashad et al., 1956) e, à medida que aumenta a senescência, há translocação para os rizomas e tubérculos (Heredia, 1988). Daí, os aumentos produtivos de rizomas obtidos até os 330 dias após o plantio nas plantas tutoradas (Figura 2) e o aumento de $11,42 \%$ na produção total da cultura rasteira em relação à tutorada, no clone Caramujo, foram devido ao aumento produtivo de tubérculos (Figura 3).

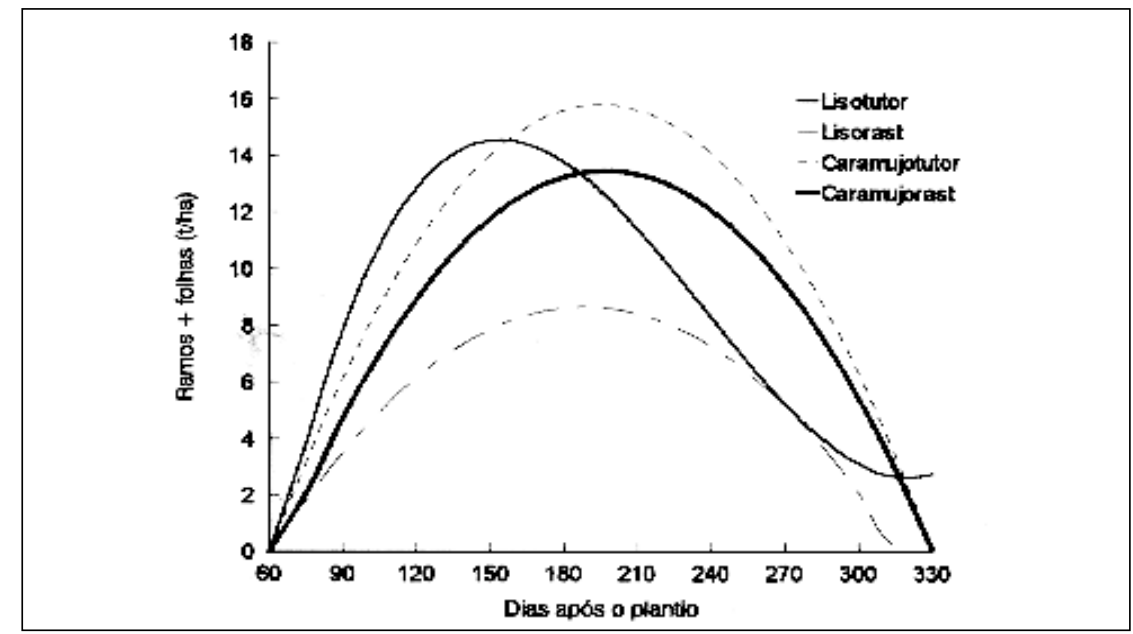

Figura 1. Produção de ramos + folhas (t/ha), de dois clones de cará, tutorados e rasteiros. Dourados-MS, UFMS, 1996.
Liso tutor $\quad \cdot=-35,28+0,77 \mathrm{D}-0,00370 \mathrm{D} 2+0,0000053 \mathrm{D} 3 ; \quad \mathrm{R} 2=0,79$
$\begin{array}{lll}\text { Liso rast } \quad \cdot=-10,22+0,20 \mathrm{D}-0,00053 \mathrm{D} 2 ; & \mathrm{R} 2=0,77\end{array}$
Caramujo tutor $\bullet=-17,42+0,34 \mathrm{D}-0,00087 \mathrm{D} 2 ; \quad \mathrm{R} 2=0,96$
$\begin{array}{lll}\text { Caramujo rast } \quad \cdot=-16,16+0,30 \mathrm{D}-0,00076 \mathrm{D} 2 ; & \mathrm{R} 2=0,90\end{array}$

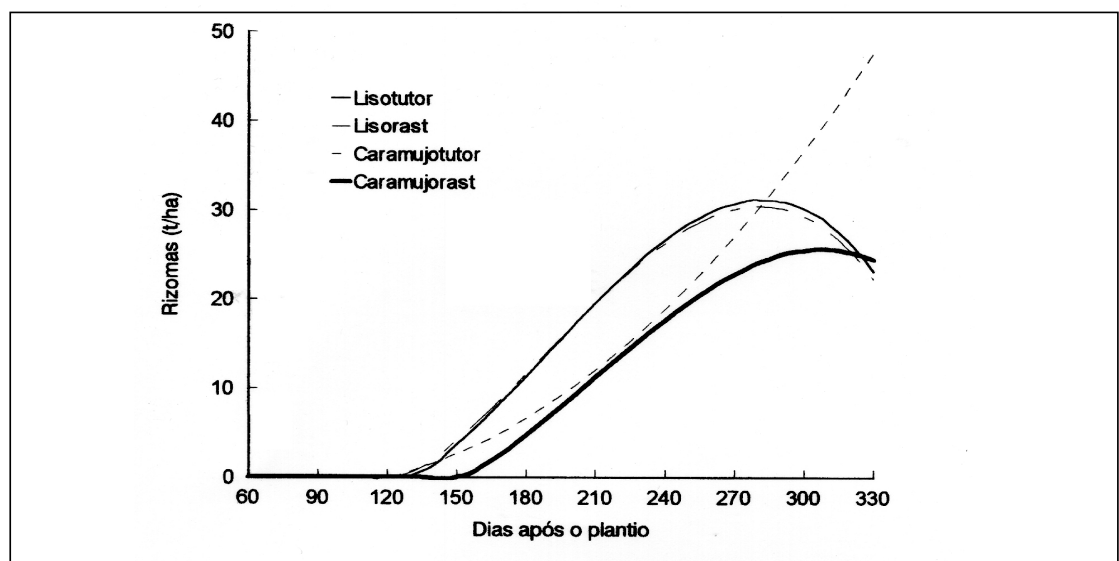

Figura 2. Produção de rizomas (t/ha) de dois clones de cará, tutorados e rasteiros. Dourados-MS, UFMS, 1996.
Liso tutor
$\bullet=35,80-0,89 \mathrm{D}+0,0062 \mathrm{D} 2-0,0000110 \mathrm{D} 3$
Liso rast
$\bullet=33,09-0,84 \mathrm{D}+0,0059 \mathrm{D} 2-0,0000100 \mathrm{D} 3$;
$\mathrm{R} 2=0,96$
Caramujo tutor $\bullet=3,26-0,12 \mathrm{D}+0,00077 \mathrm{D} 2$;
$\mathrm{R} 2=0,97$
Caramujo rast $\bullet=33,22-0,76 \mathrm{D}+0,0047 \mathrm{D} 2-0,0000075 \mathrm{D} 3 ; \quad \mathrm{R} 2=0,91$

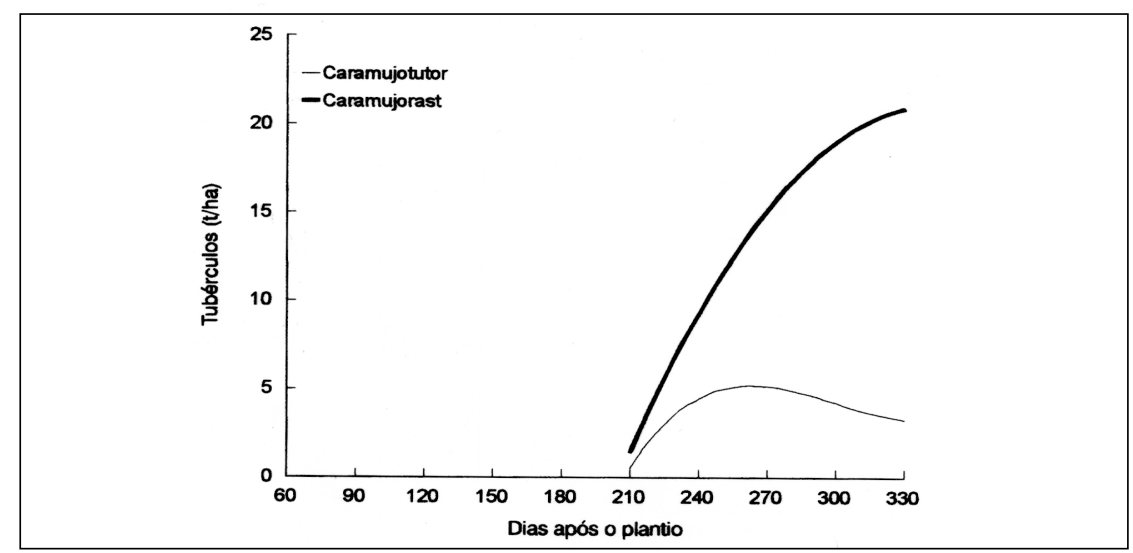

Figura 3. Produção de tubérculos (t/ha) de dois clones de cará, tutorados e rasteiros. Dourados-MS, UFMS, 1996.

Caramujo tutor $\bullet=-255,85+2,68 \mathrm{D}-0,0090 \mathrm{D} 2+0,00001 \mathrm{D} 3 ; \quad \mathrm{R} 2=0,99$

Caramujo rast $\bullet=-109,54+0,76 \mathrm{D}-0,0011 \mathrm{D} 2 ; \quad \mathrm{R} 2=0,98$ 
Tabela 1. Composição nutritiva de componentes amídicos dos clones de cará Liso e Caramujo. Dourados-MS, UFMS , 1996

\begin{tabular}{lccc}
\hline \multirow{2}{*}{ Composição nutritiva ${ }^{1 /}$} & \multicolumn{3}{c}{ Clones } \\
\cline { 2 - 4 } & \multicolumn{2}{c}{ Caramujo } & Liso \\
\cline { 2 - 4 } & Tubérculos & Rizomas & Rizomas \\
\hline Umidade e voláteis à $105^{\circ} \mathrm{C}$ p/p & 81,30 & 80,00 & 78,90 \\
Resíduo mineral fixo \% p/p & 0,60 & 0,60 & 0,70 \\
Extrato etéreo \% p/p & 0,05 & 0,05 & 0,04 \\
Proteínas (N x 6,25) \% p/p & 1,60 & 1,80 & 2,60 \\
Açúcares totais em amido \% p/p & 13,80 & 15,80 & 17,40 \\
Fibra detergente neutro \% p/p & 0,80 & 0,90 & 0,40 \\
Valor calórico total kcal/100 g & 62,05 & 70,85 & 80,36 \\
Matéria seca \% p/p & 18,70 & 20,00 & 21,10 \\
\hline 1/ Dados determinados no Laboratório de Tecnologia de Alimentos da UFMS, em Campo \\
Grande - MS.
\end{tabular}

Pela produção de tubérculos do clone Caramujo, constata-se a necessidade de os ramos estarem em contato com o solo para apresentar crescimento em tamanho e peso como pode ser confirmado com os valores crescentes obtidos nas plantas rasteiras e a baixa produção, com estabilização, nas plantas tutoradas, onde os tubérculos obtidos foram de poucos ramos em contato com o solo. Isso confirmaria o exposto por Hashad et al. (1956) de que os fotossintatos são translocados das folhas para os ramos e, finalmente, para os locais de armazenamento. Além disso, o conteúdo de fotossintatos dos ramos varia com a velocidade de translocação durante o crescimento, e com o grau de utilização em processos metabólicos envolvidos na formação de novos tecidos.

Ao relacionar as produções totais (rizomas e tubérculos) dos clones, aos 330 dias após o plantio, independente da forma de condução da cultura, foi observado que o Caramujo (50,266 t/ha) produziu $181,58 \%$ a mais que o Liso $(22,685 \mathrm{t} / \mathrm{ha})$. Quando consideradas as produções por planta, observou-se que as plantas do Caramujo conduzidas de forma rasteira $(15,896 \mathrm{~kg} /$ planta $)$ produziram $122,85 \%$ a mais que aquelas tutoradas $(7,133 \mathrm{~kg} /$ planta) do mesmo clone e $138,07 \%$ e $358,36 \%$ a mais que as plantas do clone Liso, conduzidas de forma rasteira $(6,677 \mathrm{~kg} /$ planta $)$ e tutorada $(3,468 \mathrm{~kg} /$ planta $)$, respectivamente.

Pelas análises do valor nutritivo dos componentes amídicos dos clones de cará (Tabela 1), concluiu-se que os rizomas do 'Liso' foram os melhores. Os menores conteúdos de matéria seca, amido e fibra dos tubérculos do cará Caramujo podem dever-se à fonte de translocação ter sido os ramos e folhas na sua fase de senescência (Figura 1) e que coincidiu com o maior crescimento dos tubérculos (Figura 3).
Considerando os custos para o cultivo de cará tutorado e em razão da baixa diferença produtiva com a condução rasteira, no caso do 'Liso', pode-se recomendar o cultivo dos clones de cará Liso e Caramujo, em forma rasteira.

\section{LITERATURA CITADA}

A GRANJA DO ANO. Cará e inhame. São Paulo: Centaurus, p. $30-35,1994$.

ABRAMO, M.A. Taioba, cará e inhame: o grande potencial inexplorado. São Paulo: İcone, 1990, $80 \mathrm{p}$.

APEZZATO-DA-GLÓRIA, B. Anatomia de sistemas subterrâneos. In: CONGRESSO LATINO-AMERICANO DE RAÍZES TROPICAIS, 1, CONGRESSO BRASILEIRO DE MANDIOCA, 9. São Pedro-SP, 1996. Programa e resumos. São Pedro, CERAT/ UNESP, SBM, p. 45 - 51, 1996.

GOMES, J.M. Sistema para análises estatisticas e genéticas (SAEG). Viçosa: Central de Processamento de dados, UFV, 1992, $100 \mathrm{p}$.

HASHAD, M.N.; STINO, K.R.; EL-HINNAMY, S.I. Transformation and translocation of carboidrates in taro plants during growth. Annual Agriculture Science, v. 1, n. 1, p. 262 - 267, 1956.

HEREDIA Z., N.A. Curvas de crescimento de inhame (Colocasia esculenta (L.) Schott), considerando cinco populações, em solo seco e alagado. Viçosa: UFV, 1988, 95 p. (Tese doutorado)

HEREDIA Z., N.A.; VIEIRA, M.C. Produção de dois clones de cará (Dioscorea sp), considerando três populações, em Dourados-MS. SOBInforma, Curitiba, v. XIII, n. 2, p. 24 26, 1994.

LARCHER, W. Ecofisiologia vegetal. São Paulo: Pedagógica e Universitária Ltda, 1986, $319 \mathrm{p}$.

STRAUSS, M.A. Anatomy and morphology of taro: Colocasia esculenta (L.) Schott. In: WANG, J.K. Taro: a review of Colocasia esculenta and its potential. Honolulu, University of Hawaii Press, p. 21 - 23, 1983.

VIDAL, W.N.; VIDAL, M.R.R. Botânica organografia: quadros sinóticos ilustrados de fanerógamos. 3 ed., Viçosa, UFV, 114 p. 1992.

VIEIRA, M.C. Avaliação do crescimento e da produção de clones e efeito de residuo orgânico e de fósforo em mandioquinha-salsa no Estado de Mato Grosso do Sul. Viçosa: UFV, 1995, 146 p. (Tese doutorado). 